\title{
Updating Large Scale Topographic Databases in Italian Urban Areas with Submeter QuickBird Images
}

\author{
Marco Gianinetto \\ Remote Sensing Laboratory, DIIAR Department, Politecnico di Milano University, Piazza Leonardo da Vinci 32, 20133 Milano, Italy \\ Correspondence should be addressed to Marco Gianinetto, marco.gianinetto@polimi.it
}

Received 6 June 2007; Revised 9 November 2007; Accepted 2 January 2008

Recommended by Paul Cross

This paper presents some tests for the updating of the Italian Raster Regional Technical Map (RRTM) at 1: 10000 scale and of the Italian Vector Technical Map (VTM) at 1: 5000 scale using a submeter Quickbird imagery collected in a near flat urban area of the Northern Italy. Results show that the updating of the 1: 10000 scale cartography was always possible, while a rigorous updating of 1: 5000 scale cartography was possible only in few situations. Results are discussed with reference to the specifications required for the 1: 10000 scale and 1: 5000 scale topographic databases (DBs) production of the Lombardia Region, which is a reference for metric mapping purposes in Italy.

Copyright (c) 2008 Marco Gianinetto. This is an open access article distributed under the Creative Commons Attribution License, which permits unrestricted use, distribution, and reproduction in any medium, provided the original work is properly cited.

\section{INTRODUCTION}

Urban planning using digital aerial photos has become very popular in the past several years, but the use of satellite images for urban mapping and cartographic update was limited by image resolution [1], even if mapping agencies shown great interest in its possible use for their data collection programs. From the end of 1990s, with the successful launch of the first commercial high-resolution satellite, IKONOS, a new source of imagery has been available to the civilian spatial-data users and many proposals concerning the use of satellite images for map updating started to appear in literature [2-5].

There are several advantages of updating existing topographic maps using satellite images instead of aerial photos. First of all, a single satellite scene covers a large area (from less than $65 \mathrm{~km}^{2}$ for OrbView-3 to more than $270 \mathrm{~km}^{2}$ for QuickBird). Hence, the survey costs may be reduced. Moreover, with few exceptions (e.g., EROS-B), satellite data are multispectral, so they can be also used for thematic mapping purposes (this also applies to the photogrammetric digital cameras such as Leica ADS-40 or Z/I Imaging DMC). Finally, and that is the most important factor, remotely sensed images of a specific site can be collected with very short revisit time. Consequently, it is possible to quickly update the existing cartography, also in areas that were previously too remote or too dangerous to reach using conventional aerial photography.
The geometric correction of such data has been well studied in past years [6-12] and orthorectified images have proved to be a useful data source for the creation and the updating of mapping products [3]. However, the highresolution images captured from satellites have been mainly used in the mapping and surveillance of otherwise inaccessible areas, such as areas of military conflict as Afghanistan or Iraq $[13,14]$. Some tests have also been carried on to generate new maps in parts of the world that do not have a tradition of detailed mapping [15].

In well-mapped countries, such as Western Europe, detailed topographic databases (DBs) have been (or are being) built using both field surveys and aerial surveys. Therefore, the main task of the national mapping agencies is the updating of the existing topographic databases (DBs) rather than the creation of new topographic maps. The results of an OEEPE (now EuroSDR) report (2003), undertaken by several European mapping agencies and institutions about the use of IKONOS data for mapping purposes, suggested that this kind of images can be potentially used for cartographic updating at scales between $1: 50000$ and $1: 10000$ and a study of Ordnance Survey (2004), Great Britain's National Mapping Agency, found that QuickBird imagery can be used to update maps between 1:10000 scale and 1: 6000 scale as long as small linear features were excluded from the mapping specifications [3]. Moreover, only recently high-resolution satellite images have been adopted as a data source in large projects, 
such as the IKONOS complete coverage of the Flemish region $\left(13,512 \mathrm{~km}^{2}\right)$ taken in 2003 for the Flemish Land AgencyGeographical Information System Flanders Support Centre Department [16].

Regarding the extraction of topographic features from high-resolution images, in past years many tests have been done primarilyfor road networks extraction and buildings detection (for more details, see [17]) or for GIS updating $[18,19]$. Topographic map and topographic database updating was also considered [3, 5, 20-22], but very few literature exists on the comparison between the mapping accuracy which can be obtained from high-resolution satellite images and the actual requirements for large scale map production in well-mapped countries.

This paper presents some tests for the updating of the Italian Raster Regional Technical Map (RRTM) at 1:10000 scale and of the Italian Vector Technical Map (VTM) at 1 : 5000 scale using submeter QuickBird imagery. Results are discussed with reference to the specifications required for the traditional $1: 10000$ scale and $1: 5000$ scale topographic DBs production of the Lombardia Region [23], which is a reference for metric mapping purposes in Italy.

\section{ITALIAN MAPPING SPECIFICATIONS}

Italy is a well-mapped country and the infrastructures required to capture and process aerial photography are well established. The basic cartography for the regional planning is the Regional Technical Map (RTM) at 1: 10000 scale and all the country is mapped at that scale using traditional field surveys and aerial surveys. The production and the updating of the RTM are in charge of the regional governments (20 in all), and each one makes its rules and specifications for its production, even though in a technical roundtable state, regions and local administrations are trying to define some common specifications for general purposes topographic DBs [24].

Today, aerial digital orthophotos are largely employed in many Italian Regions as supplementary data to traditional cartography and also high-resolution satellite data are being increasingly used, however, until now, no official cartographic products have been produced in Italy from them. The reason may be found in the lack of rules. In fact (with few exceptions), at the present time there is no specific legislation in Italy for the creation and the updating of topographic maps using digital orthophotos or satellite images.

The main problem that users must cope with when working with the RTM is its oldness: the RTM is supposed to be updated approximately every 10-15 years, consequently it may be very dated. In this context, high-resolution remote sensing could be easily used for a quick updating of the existent RTMs and associated databases of geospatial information.

Because no specific rules actually exist, here we refer to the mapping technical specifications for the traditional 1 : 10000 scale and 1:5000 scale topographic DBs of the Lombardia Region, which is the reference for metric mapping purposes. In particular, the tests carried on refer to the technical specifications version $01 / 01$ [27] that defines the planimetric tolerance allowed for the positioning of single points in a map as follows:

$$
\begin{array}{r}
\sqrt{\left(N_{m}(p)-N_{g}(p)\right)^{2}+\left(E_{m}(p)-E_{g}(p)\right)^{2}} \leq 2.00 m \\
\text { for } 1: 5000 \text { scale map, } \\
\sqrt{\left(N_{m}(p)-N_{g}(p)\right)^{2}+\left(E_{m}(p)-E_{g}(p)\right)^{2}} \leq 4.00 m \\
\text { for } 1: 10000 \text { scale map, }
\end{array}
$$

where $N_{m}(p)$ is the north coordinate of the point $p$ measured on the map, $E_{m}(p)$ is the east coordinate of the point $p$ measured on the map, $N_{g}(p)$ is the north coordinate of the point $p$ measured on the ground, $E_{g}(p)$ is the east coordinate of the point $p$ measured on the ground, and the planimetric tolerance allowed for the distances between two points in a map as follows:

$$
\begin{aligned}
& \left|D_{m}(p, q)-D_{g}(p, q)\right| \leq\left(2.00+\frac{D_{g}(p, q)}{1000}\right) m \\
& \quad \text { for } D_{g} \leq 800 m, \text { for } 1: 5000 \text { scale map; }
\end{aligned}
$$

$$
\left|D_{m}(p, q)-D_{g}(p, q)\right|
$$

$\leq 2.80 m$, for $D_{g}>800 m$, for $1: 5000$ scale map,

$$
\begin{aligned}
& \left|D_{m}(p, q)-D_{g}(p, q)\right| \leq\left(4.00+\frac{D_{g}(p, q)}{1000}\right) m \\
& \quad \text { for } D_{g} \leq 1500 m \text {, for } 1: 10000 \text { scale map, } \\
& \left|D_{m}(p, q)-D_{g}(p, q)\right| \\
& \quad \leq 5.50 m, \text { for } D_{g}>1500 m \text {, for } 1: 10000 \text { scale map, }
\end{aligned}
$$

where $D_{m}(p, q)$ is the distance between the points $p$ and $q$ measured on the map, $D_{q}(p, q)$ is the distance between the points $p$ and $q$ measured on the ground.

When a map is produced or updated it must be tested. This operation is carried out by measuring a set of points and distances on the map and their correspondent on the ground, measured with a higher precision. As far as the statistical distribution of the residuals is always considered to be a Gaussian function, a map is approved when $95 \%$ of all the testing measures fall within the tolerances defined with (1)-(2).

Because here we refer only to the planimetric updating of existing maps (not derived from stereo pairs), the tolerances for the elevation were not taken into consideration.

\section{CASE STUDY}

A case study was carried out in the council area of $\mathrm{Ce}$ sano Maderno, one of the municipalities in the surroundings of Milano (Lombardia), in northern Italy. The territory of Cesano Maderno is almost flat and has a full surface of $11.46 \mathrm{~km}^{2}$. The elevation range varies from $194 \mathrm{~m}$ to $228 \mathrm{~m}$ above sea level, increasing from south to north, and the urban structure is that typical of small Italian towns: a dense 


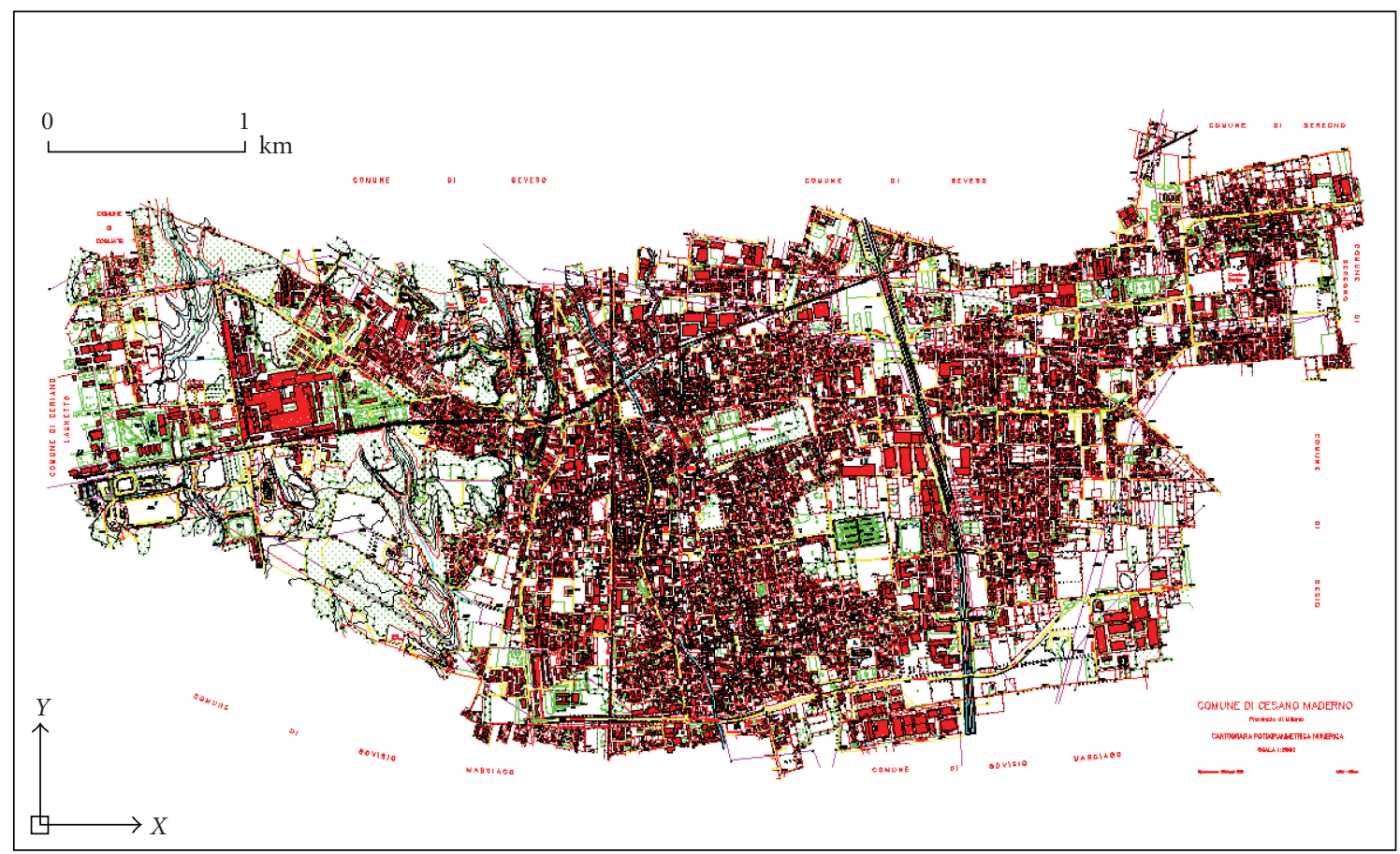

FIgURE 1: 1:2000 scale vector cartography of Cesano Maderno.

old town centre with a sparse surrounding of detached house and industrial/commercial areas.

\subsection{Dataset}

The source dataset used was composed of the following:

(1) one $0.70 \mathrm{~m}$ panchromatic QuickBird image of the surroundings of Milano (Lombardia, Italy), collected on May 3, 2003 with $15^{\circ}$ off-nadir angle (upper left corner latitude $45.7138^{\circ}$, upper left corner longitude $\left.9.3008^{\circ}\right)$

(2) one $2.80 \mathrm{~m}$ multispectral QuickBird image of the surroundings of Milano, collected on May 3, 2003 with $15^{\circ}$ off-nadir angle (upper left corner latitude $45.7138^{\circ}$, upper left corner longitude $9.3008^{\circ}$ );

(3) the Raster Regional Technical Map (RRTM) at 1 : 10000 scale, produced in 1994 traditional aerial surveys and supplied by the Cartographic Office of the Lombardia Regional Government;

(4) a vector cartography of the city of Cesano Maderno at $1: 2000$ scale, produced in 1999 using traditional aerial and topographic surveys and supplied by the municipality of Cesano Maderno (see Figure 1);

(5) the Vector Technical Map (VTM) of the city of Cesano Maderno at $1: 5000$ scale, produced as generalization of the $1: 2000$ scale vector cartography and supplied by the municipality of Cesano Maderno.

Accuracy of source raster and vector cartography is shown as follows.

(1) Vector cartography (1:2000 scale): better than $0.80 \mathrm{~m}$ in plan and better than $0.60 \mathrm{~m}$ in elevation;
(2) Vector Regional Technical Map (1 : 5000 scale): better than $0.80 \mathrm{~m}$ in plan because it is derived as generalization of the $1: 2000$ scale vector map;

(3) Raster Regional Technical Map (1:10 000 scale): better than $4 \mathrm{~m}$ in plan.

\subsection{Data processing}

\subsubsection{Pan-sharpening}

Image fusion is the combination of multiple images into composite products, used to reveal more information than that of individual input images. Pan-sharpening describes a process of transforming a set of low spatial resolution multispectral (color) images into higher spatial resolution color images by fusing a coregistered fine spatial resolution panchromatic (black and white) image.

During the past years, different pan-sharpening methods have been developed, such as those based on multiresolution wavelet transforms, on the principal component analysis transforms, or on the intensity-hue-saturation transforms. Recently, with the increasing use of high-resolution satellite images for urban analysis, several new pan-sharpening techniques have been proposed with the aim of preserving the color fidelity in the pan-sharpened images [25].

In urban mapping applications, pan-sharpening can be successfully used to spectrally enhance the high-resolution panchromatic satellites data by adding the color information derived from the multispectral images. As a consequence, pan-sharpened images offer a superior capability for the human interpretation of the territory.

Since in this study the map updating was carried out by manual digitization, the QuickBird image was preprocessed 


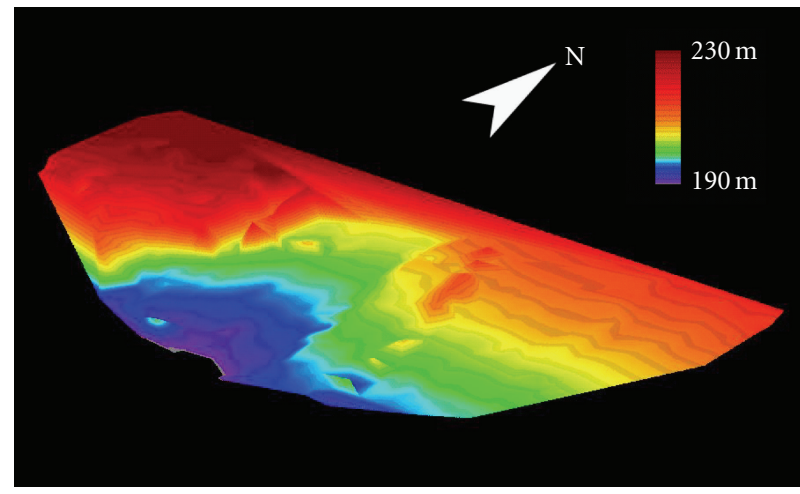

Figure 2: Digital elevation model derived from the $1: 2000$ scale vector cartography of Cesano Maderno. The elevation range varies from 194 to 228 meters above sea level, increasing from south to north.

by fusing together the $0.70 \mathrm{~m}$ panchromatic band and the $2.80 \mathrm{~m}$ multispectral bands using the Gram-Schmidt spectral sharpening method, invented by Laben and Brower in 1998 and patented by Eastman Kodak [26]. Further analysis was performed on the pan-sharpened imagery.

\subsubsection{Digital elevation model generation and ground control points selection}

When not using stereo couples, a digital elevation model (DEM) is required for the geometric correction of data. Consequently, a $50 \mathrm{~m}$ grid spacing DEM was derived by interpolating many hundreds of ground elevation data extracted from the 1:2000 scale cartography (see Figure 2).

Again from the 1:2000 scale cartography, 110 ground points characterized by an accuracy better than $0.80 \mathrm{~m}$ in plan and with a regular geometric distribution over the whole study area were selected and measured. Subsequently, these points were divided into two datasets: (1) 80 ground control points (GCPs) used for the image orthorectification and (2) 30 points used as independent check points (ICPs) for evaluating the orthorectification accuracy (see Figure 3).

\subsubsection{Image orthorectification}

Because no metadata or Rational Polynomial Coefficients (RPCs) were available, the QuickBird image was geometrically corrected using two different nonparametric techniques: (1) the Rational Function Model (RFM) with RPCs computed from GCPs and (2) the spline interpolation computed from GCPs.

Several orthoimages were generated both using the RFM and the spline methods and using an increasing number of GCPs: from 40 to 80 . Their accuracy was checked by manually measuring on the corrected images the cartographic coordinates of the 30 ICPs previously identified. Table 1 shows a summary of results.

In our tests, the RFM method led to superior results than the spline method. With respect to splines, the accuracy of the orthoimages did not vary significantly from the use of
40 GCPs to 80 GCPs. In the former case, it was obtained a $0.60 \mathrm{~m}$ root mean square error for the East coordinate $\left(\mathrm{RMSE}_{E}\right), 1.55 \mathrm{~m}$ root mean square error for the North coordinate $\left(\mathrm{RMSE}_{N}\right)$, and $1.66 \mathrm{~m}$ overall root mean square error (RMSE), while in the latter case it was observed a $0.57 \mathrm{~m}$ $\mathrm{RMSE}_{E}, 1.51 \mathrm{~m} \mathrm{RMSE}{ }_{N}$, and $1.62 \mathrm{~m}$ overall RMSE.

Concerning the RFM method, the best result was obtained using a full 3rd-order RFM using 80 GCPs $(0.50 \mathrm{~m}$ $\mathrm{RMSE}_{\mathrm{E}}, 1.10 \mathrm{~m} \mathrm{RMSE}$, and $1.21 \mathrm{~m}$ overall RMSE). With increasing the number of GCPs from 40 to 60 , the accuracy of the geometric correction passed from $0.62 \mathrm{~m} \mathrm{RMSE}_{\mathrm{E}}, 2.14 \mathrm{~m}$ RMSE $_{\mathrm{N}}$, and $2.22 \mathrm{~m}$ overall RMSE to $0.55 \mathrm{~m}$ for RMSE $\mathrm{E}_{\mathrm{E}}$, $1.11 \mathrm{~m} \mathrm{RMSE}_{\mathrm{N}}$, and $1.24 \mathrm{~m}$ overall RMSE, respectively. No further significant improvement was instead observed using more GCPs.

\subsubsection{Vector extraction}

Vector cartography for three quarters of Cesano Maderno was manually extracted from the pan-sharpened orthorectified QuickBird image and then used for simulating a topographic DB updating of both the $1: 5000$ scale VTM and the $1: 10000$ scale RRTM. The simulation was carried out by wiping out some quarters from the existing cartography and replacing them with the vector layers extracted from the QuickBird image.

From the 12 classes defined for buildings in the mapping technical specifications and from the 11 classes defined for roads, the simulation took into consideration only the following 8 classes (one for roads and six for buildings).

Class 1: roads.

Class 2: civilian buildings.

Class 3: local government buildings.

Class 4: commercial buildings.

Class 5: industrial buildings.

Class 6: churches and places of cult.

Class 7: shack/roof.

Furthermore, buildings were digitized from tops because footprints were rarely visible due to both the dense urbanization texture and the presence of long shades caused by the tilted viewing geometry.

Finally, results were assessed by comparing the QuickBird derived vectors with the higher precision $1: 2000$ scale cartography.

\section{RESULTS AND DISCUSSION}

Because the planimetric position of objects in the images is influenced by the relief displacement due to differences in the relative elevation of objects, and the taller the object the greater the relief displacement, buildings usually show an incorrect positioning in relation to their height. Besides, when using off-nadir collected images such as highresolution satellite data, the satellite's tilt angle introduces a further source of error. For that reason, the mapping accuracy was tested separately analyzing three different types of urban texture, characterized by a different elevation range of buildings: (1) a mixture of industrial/commercial area and 


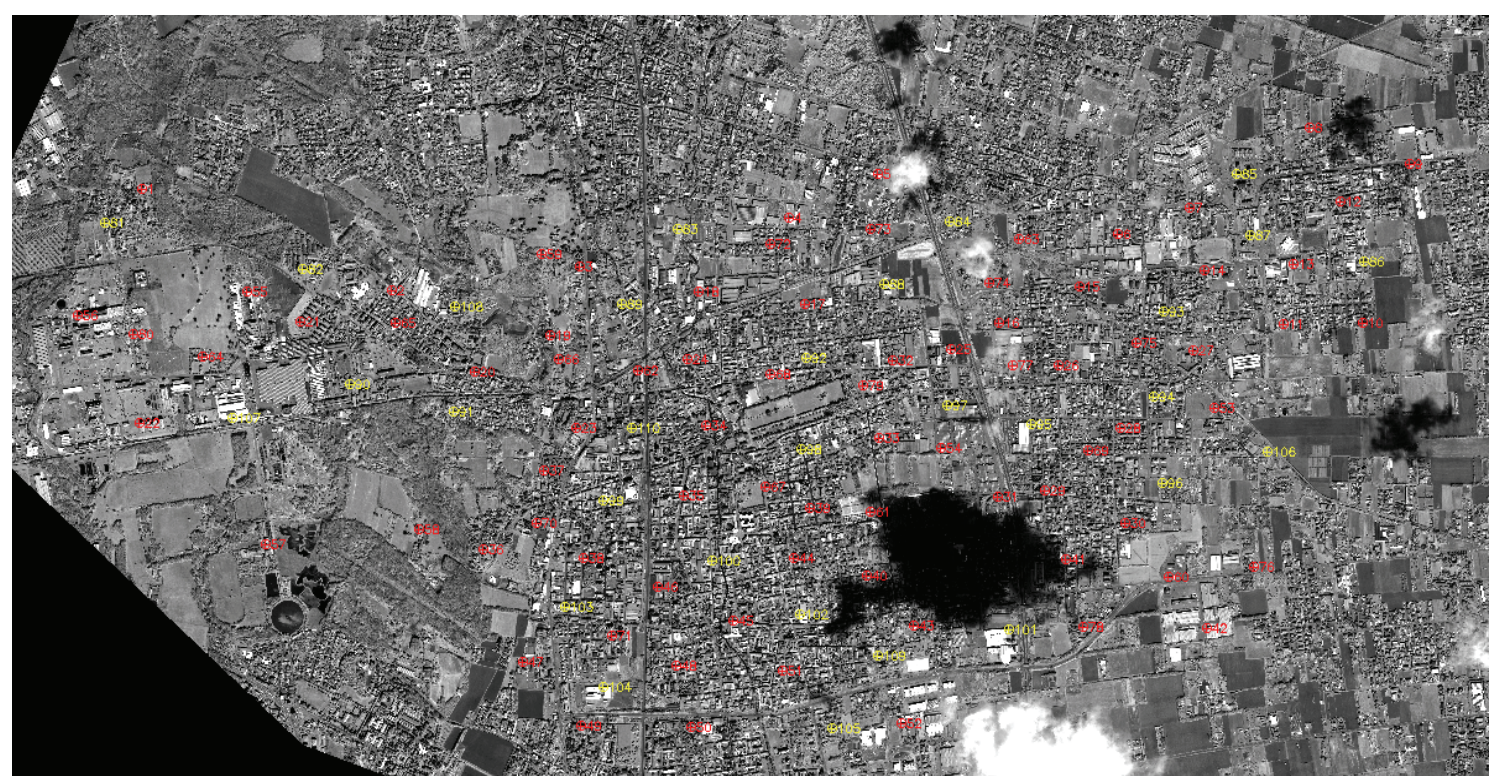

FIGURE 3: Geometric distribution of ground control points (red crosses) and independent check points (yellow crosses).

TABLE 1: Accuracy of the orthoimages generated using the rational function model and the spline interpolation methods, calculated on the basis of 30 independent check points.

\begin{tabular}{lllll}
\hline \multirow{3}{*}{ Method } & $\begin{array}{l}\text { GCPs } \\
\text { (nr.) }\end{array}$ & East & North & Overall \\
\hline \multirow{4}{*}{ RFM } & 40 & 0.62 & 2.14 & 2.22 \\
& 50 & 0.58 & 1.41 & 1.52 \\
& 60 & 0.55 & 1.11 & 1.24 \\
& 70 & 0.51 & 1.12 & 1.23 \\
& 80 & 0.50 & 1.10 & 1.21 \\
\multirow{3}{*}{ Spline } & 40 & 0.60 & 1.55 & 1.66 \\
& 50 & 0.55 & 1.45 & 1.55 \\
& 60 & 0.61 & 1.49 & 1.61 \\
& 70 & 0.60 & 1.50 & 1.61 \\
& 80 & 0.57 & 1.51 & 1.62 \\
\hline
\end{tabular}

residential area with buildings with very different heights (between 2 and 7/8 floors), called category A; (2) a dense urban area typical of Italian cities (about $3 / 4$ floors), called category B, and (3) an urban area of detached houses with small, regular, and similar buildings (single storey or 2 floors), called category C. For each category, the tolerances required for the $1: 10000$ scale and $1: 5000$ scale topographic DB of the Lombardia Region were tested, as defined in (1)-(2).

\subsection{Positioning accuracy}

Regarding the positioning accuracy of single points, the coordinates of 1,158 points were checked: 240 for category A, 319 for category B, and 599 for category C. The different numbers of point measures for the different categories were representative of the number of buildings digitized for each category (see Figure 4).
For the $1: 5000$ map scale update, $13 \%$ of measurements were outside the tolerance limit for category A, $8 \%$ were outside the tolerance limit for category B, and only $2 \%$ were outside the tolerance limit for category $\mathrm{C}$. Thus, the test was passed only for urban area of detached houses (see Table 2).

For the $1: 10000$ map scale update, all the measures were within the tolerance limit, regardless of the urban typology. Thus, the test was passed for all urban areas (see Table 2).

\subsection{Distances accuracy}

Regarding the distances between two points, they were calculated from pairs of points used in the previous tests. However, after having verified that points very close to each other (typically points belonging to the same building) had very small distance errors, a limited number of measures belonging to both the shorter range $(<800 \mathrm{~m})$ and the longer range $(800 / 1500 \mathrm{~m})$ were selected, resulting in a fewer number of measures. Thus, 187 distance measures were checked: 41 for category A, 82 for category B, and 64 for category C (see Figure 4).

For the $1: 5000$ map scale update, $7 \%$ of measurements were outside the tolerance limit for category A, $1 \%$ were outside the tolerance limit for category B, and all were within the tolerance limit for category $\mathrm{C}$. Therefore, the test was passed both for the dense urban area and for the urban area of detached houses (see Table 3).

For the $1: 10000$ map scale update all the measures were within the tolerance limit, regardless of the urban typology. Thus, the test was passed for all urban areas (see Table 3 ).

\subsection{Final editing}

A final editing is always needed to give the cartographic dressing and to correct any little inaccuracies. Figure 5 shows some little overlaps between the building and the road classes which were removed in editing. 


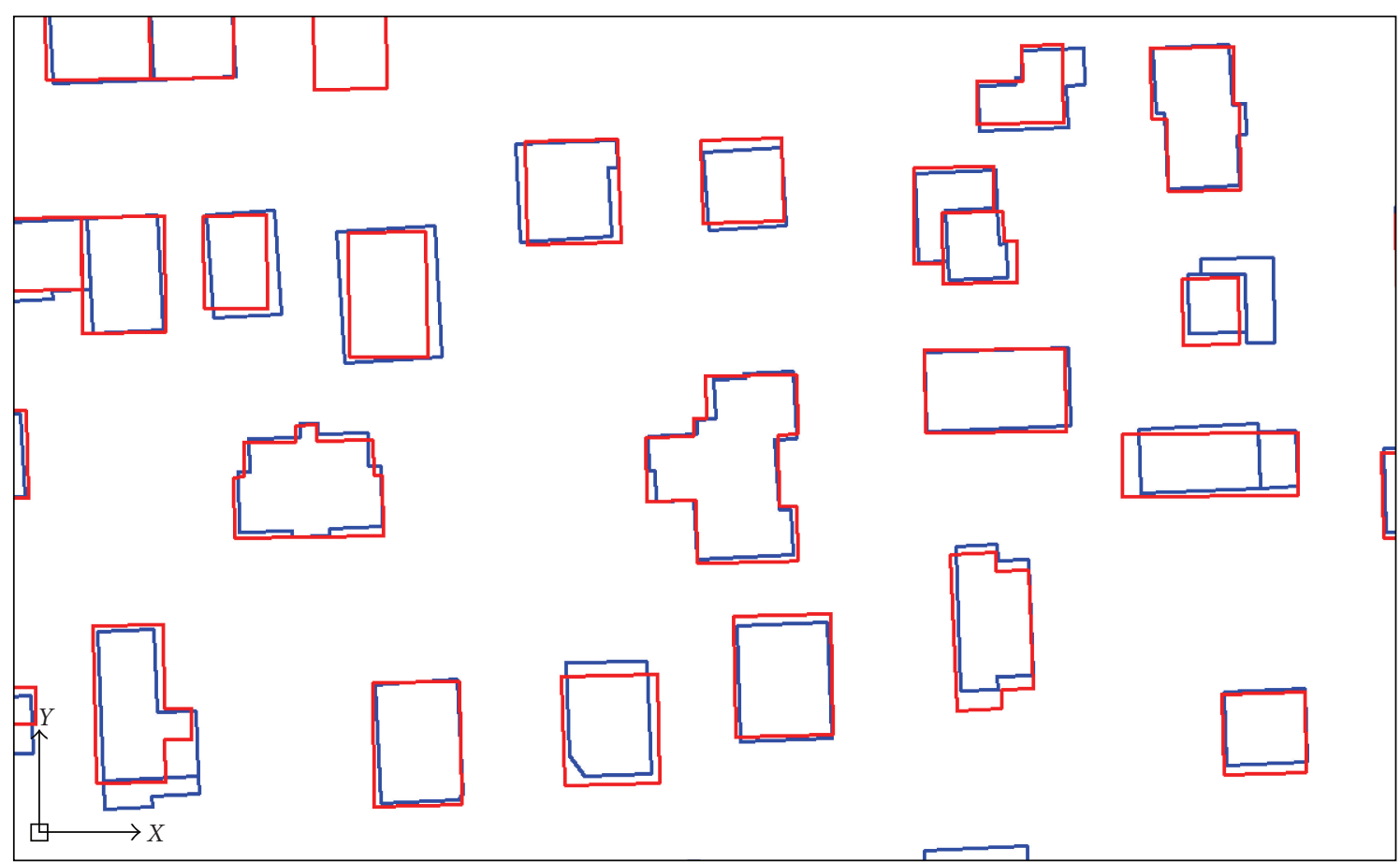

FIGURE 4: Example comparison between the buildings digitized from the QuickBird image (red lines) and homologous buildings from the 1 : 2000 vector cartography (blue lines).

TABLE 2: Results of the cartographic tests for the positioning of single points.

\begin{tabular}{|c|c|c|c|c|c|c|}
\hline \multirow{2}{*}{$\begin{array}{l}\text { Urban typology } \\
\text { Map scale }\end{array}$} & \multicolumn{2}{|c|}{ Category A } & \multicolumn{2}{|c|}{ Category B } & \multicolumn{2}{|c|}{ Category C } \\
\hline & $1: 5000$ & $1: 10000$ & $1: 5000$ & $1: 10000$ & $1: 5000$ & $1: 10000$ \\
\hline Testing measures (nr.) & 240 & 240 & 319 & 319 & 599 & 599 \\
\hline Within tolerance limit & $87 \%$ & $100 \%$ & $92 \%$ & $100 \%$ & $98 \%$ & $100 \%$ \\
\hline Outside tolerance limit & $13 \%$ & $0 \%$ & $8 \%$ & $0 \%$ & $2 \%$ & $0 \%$ \\
\hline Test pass & No & Yes & No & Yes & Yes & Yes \\
\hline
\end{tabular}

TABLE 3: Results of the cartographic tests for the mutual distances between two points.

\begin{tabular}{|c|c|c|c|c|c|c|}
\hline \multirow{2}{*}{$\begin{array}{l}\text { Urban typology } \\
\text { Map scale }\end{array}$} & \multicolumn{2}{|c|}{ Category A } & \multicolumn{2}{|c|}{ Category B } & \multicolumn{2}{|c|}{ Category $\mathrm{C}$} \\
\hline & $1: 5000$ & $1: 10000$ & $1: 5000$ & $1: 10000$ & $1: 5000$ & $1: 10000$ \\
\hline Testing measures (nr.) & 41 & 41 & 82 & 82 & 64 & 64 \\
\hline Within tolerance limit & $93 \%$ & $100 \%$ & $99 \%$ & $100 \%$ & $100 \%$ & $100 \%$ \\
\hline Outside tolerance limit & $7 \%$ & $0 \%$ & $1 \%$ & $0 \%$ & $0 \%$ & $0 \%$ \\
\hline Test pass & No & Yes & Yes & Yes & Yes & Yes \\
\hline
\end{tabular}

\subsection{Overall results}

Overall results show the following.

(1) For the mixture of industrial/commercial area and residential area (category A), it was not possible to update the 1 : 5000 scale VTM because both the positioning accuracy and the distances accuracy were outside the admitted limits, while it was possible to update the 1 : 10000 scale RRTM.

(2) For the dense urban area (category B), it was not possible to update the $1: 5000$ scale VTM because the posi- tioning accuracy was outside the admitted limit, while it was possible to update the 1: 10000 scale RRTM.

(3) For the urban area of detached houses (category C), it was always possible to update both the $1: 5000$ scale VTM and the $1: 10000$ scale RRTM.

It is to be said, however, that both the accuracy of the image orthorectification and the tolerances for the positioning and distances were checked against ICPs derived from $1: 2000$ scale cartography, so with an accuracy better than $0.80 \mathrm{~m}$ in plan. If compared to the $1: 10000$ scale RRTM requirements, the ICPs may be assumed as high precision 


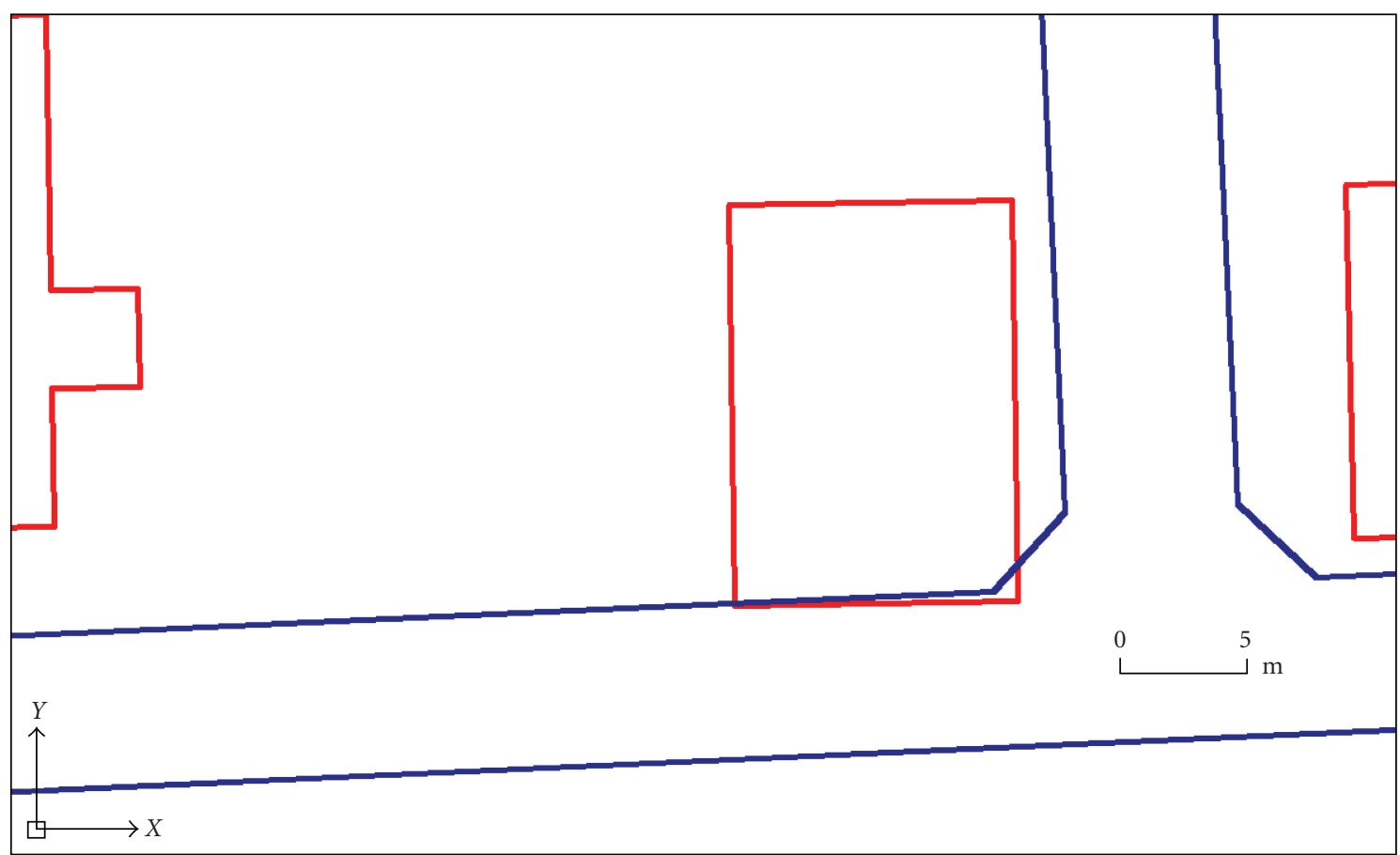

FIGURE 5: Example of overlaps between the buildings (red) and the road (blue) classes before the final editing.

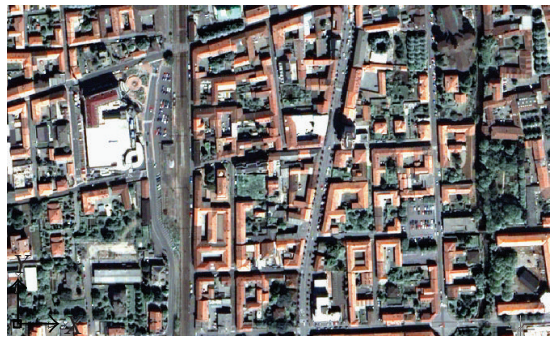

(a)

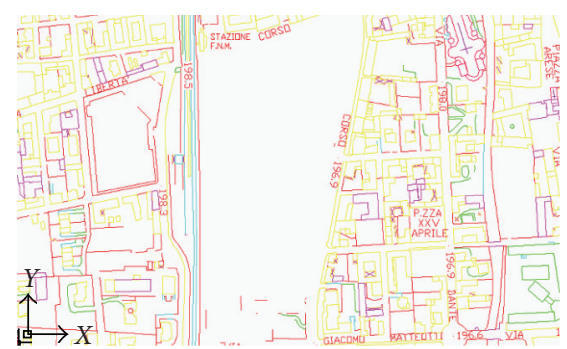

(c)

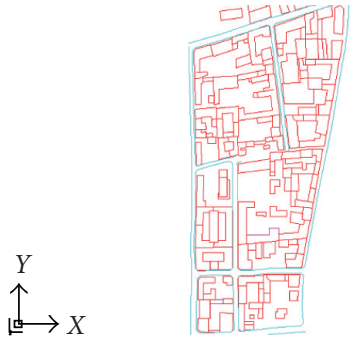

(b)

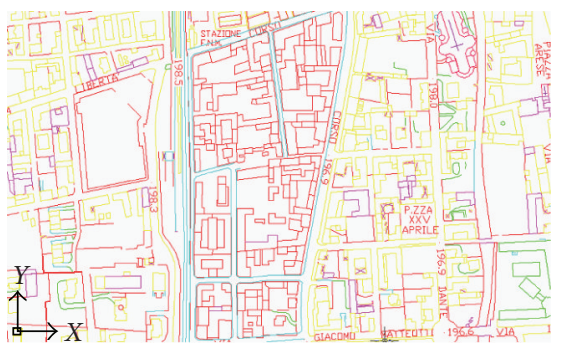

(d)

Figure 6: Simulation of 1 : 5000 scale Vector Technical Map updating in a dense urban area (category B): (a) 0.70 m QuickBird pansharpened orthorectified image, (b) digitization of buildings and roads, (c) $1: 5000$ scale Vector Technical Map of Cesano Maderno with some neighborhoods wiped out, (d) final map updating.

control points, but if compared to the higher requirements for the $1: 5000$ scale VTM they may be not as much accurate as needed. In fact, when looking at the positioning tests (see Table 2), for category B only $3 \%$ of measures are outside the admitted limits and for category A only $8 \%$ of measures are outside the admitted limits. Furthermore, looking at the distances tests, category B is within tolerances and category A has only $2 \%$ of measures outside the admitted limits.

Regarding the presence of systematic errors in the digitized vectors, no error was observed. The mean value of the absolute residuals calculated for the 1,158 point measures showed that the worse case was obtained for category A, 


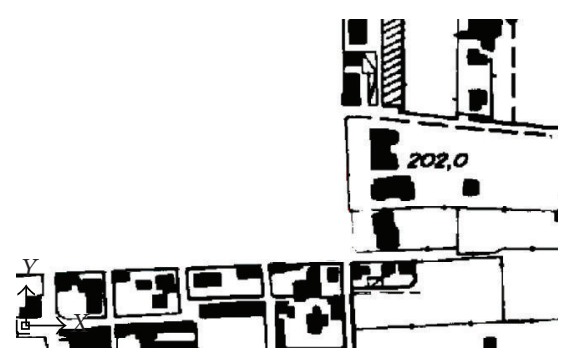

(a)

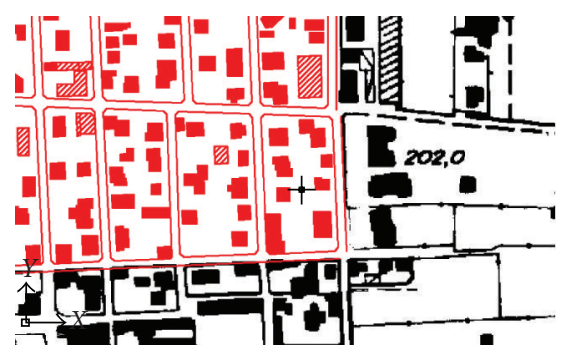

(b)

FIgURE 7: Simulation of 1:10 000 scale Raster Regional Technical Map updating in a quarter of detached houses (category C): (a) 10000 scale Raster Regional Technical Map of Cesano Maderno with some neighborhoods wiped out, (b) final map updating.

followed by category B, and finally called category C. Moreover, even for the worse case the mean value of the absolute residuals $(1.26 \mathrm{~m})$ was of the same magnitude of the orthorectification accuracy $(1.21 \mathrm{~m})$, thus confirming the absence of systematic gross errors in data. Instead, the increase in the mapping accuracy from category A to category $\mathrm{C}$ may be explained by analyzing the errors introduced by the tilted viewing geometry of the imagery used. With a $15^{\circ}$ tilt angle, buildings have a planar displacement of about $2.60 \mathrm{~m}$ every $10 \mathrm{~m}$ of high above the compensation plan used, and these errors are added (in sign) to the residuals of the orthorectification process (1.21 m overall RMSE).

Figures 6 and 7 show some simulations of the map updating, respectively, for the $1: 5000$ scale VTM and for the $1: 10000$ RRTM.

\section{CONCLUSIONS}

This study demonstrates the potentiality of high-resolution satellite images for updating existing technical cartography in developed and well-mapped countries. The map updating was discussed with reference to the legislation and the technical specifications for the traditional 1: 10000 scale and 1 : 5000 scale topographic DB of the Lombardia Region, which is a reference for metric mapping purposes in Italy. Results show that the updating of the 1: 10000 RRTM was always possible, while the rigorous updating of the $1: 5000$ scale VTM was possible only where buildings showed limited differences in the relative elevation.

Findings are in accordance with similar studies undertaken by several European mapping agencies and institutions about the use of IKONOS data for mapping purposes, suggesting the use of such kind of imagery for cartographic updating until 1 : 10000 scale map. Also Ordnance Survey, Great Britain's National Mapping Agency, found that QuickBird imagery can be used to update maps between 1:10000 scale and 1: 6000 scale, as long as small linear features were excluded from the mapping specifications.

\section{ACKNOWLEDGMENTS}

This work has been carried out under a research program partially founded by the Italian Ministry for University and Research (MIUR). The author would like to thank the municipality of Cesano Maderno (Italy) for supplying the QuickBird data and the Vector Technical Maps.

\section{REFERENCES}

[1] P. Cheng and T. Toutin, "Urban planning using data fusion of satellite and aerial photo images," in Proceedings of the IEEE International Geoscience and Remote Sensing Symposium on Remote Sensing (IGARSS '97), vol. 2, pp. 839-841, Piscataway, NJ, USA, August 1997.

[2] J. W. Seager, "A four-dimensional model for rapid mapping of linear features," Geomatica, vol. 52, no. 3, pp. 273-282, 1998.

[3] D. Holland and P. Marshall, "Updating maps in a well-mapped country using high resolution satellite imagery," in Proceedings of the 20th ISPRS International Archive of the Photogrammetry, Remote Sensing and Spatial Information Sciences , pp. 747-751, Istanbul, Turkey, July 2004, unpaginated CD-ROM.

[4] C. Armenakis, "Differential approach for map revision from new multi-resolution satellite imagery and existing topographic data," in Proceedings of the ISPRS International Archive of the Photogrammetry, Remote Sensing and Spatial Information Sciences, vol. 33, part 4/1, pp. 99-104, Amsterdam, The Netherlands, July 2000.

[5] M. Gianinetto, A. Giussani, G. Lechi, and M. Scaioni, "Fast mapping from high resolution satellite images: a sustainable approach to provide maps for developing countries," in Proceedings of the 20th International Archive of the Photogrammetry, Remote Sensing and Spatial Information Sciences, vol. 35, pp. 37-42, Istanbul, Turkey, July 2004.

[6] T. Toutin, "Multi-source data integration with an integrated and unified geometric modeling," EARSeL Journal Advances in Remote Sensing, vol. 4, no. 2, pp. 118-129, 1995.

[7] C. S. Fraser, E. Baltsavias, and A. Gruen, "Processing of IKONOS imagery for submetre 3D positioning and building extraction," ISPRS Journal of Photogrammetry and Remote Sensing, vol. 56, no. 3, pp. 177-194, 2002.

[8] W. Shi and A. Shaker, "Analysis of terrain elevation effects on IKONOS imagery rectification accuracy by using nonrigorous models," Photogrammetric Engineering \& Remote Sensing, vol. 69, no. 12, pp. 1359-1366, 2003.

[9] T. Toutin, "Review article: geometric processing of remote sensing images: models, algorithms and methods," International Journal of Remote Sensing, vol. 25, no. 10, pp. 18931924, 2004.

[10] C. V. Tao, Y. Hu, and W. Jiang, "Photogrammetric explotaition of IKONOS imagery for mapping applications," International Journal of Remote Sensing, vol. 25, no. 14, pp. 2833-2853, 2004.

[11] M. Gianinetto, "Geocoding simulation of EROS-B synchronous imagery and comparison to EROS-A1 asynchronous data," Italian Journal of Remote Sensing, vol. 36, pp. 81-92, 2006. 
[12] M. Gianinetto and M. Scaioni, "Automated geometric correction of high-resolution pushbroom satellite data," Photogrammetric Engineering \& Remote Sensing, vol. 74, no. 1, pp. 107116, 2008.

[13] M. Kumar and O. Castro, "Practical aspects of IKONOS imagery for mapping," in Proceedings of the 22nd Asian Conference on Remote Sensing, pp. 1181-1185, Singapore, November 2001, unpaginated CD-ROM.

[14] G. Petrie, "Monitoring Iraq-imagery options for monitoring and gathering intelligence," GI News, vol. 3, no. 1, pp. 28-33, 2003.

[15] P. A. Mandeville, "Jakarta Maps get a Facelift," Imaging Notes, 2001.

[16] gim-geographic information management, http://www.gim .be/gim/gim01.nsf/f1eaf5ec736fce7b80256a36005b0a12/ 87c811090e4344fbc1256dac0036d4ab?OpenDocument, 2004.

[17] E. P. Baltsavias, A. Gruen, and L. V. Gool, Eds., Automatic Extraction of Man-Made Objects from Aerial and Space Images (III), A.A. Balkema Publishers, Lisse, The Netherlands, 2001.

[18] M. Caprioli and E. Tarantino, "Accuracy assessment of perfield classification integrating very fine spatial resolution satellite imagery with topographic data," Journal of Geospatial Engineering, vol. 3, no. 2, pp. 127-134, 2001.

[19] G. Guienko and Y. Doytsher, "Geographic information system data for supporting feature extraction from high-resolution aerial and satellite images," Journal of Surveying Engineering, vol. 129, no. 4, pp. 158-164, 2003.

[20] T. Ohlhof, T. Emge, W. Reinhardt, K. Leukert, C. Heipke, and K. Pakzad, "Generation and update of VMAP data using satellite and airborne imagery," in Proceedings of the 33th ISPRS International Archive of the Photogrammetry, Remote Sensing and Spatial Information Sciences, vol. 33, pp. 762-768, Amsterdam, The Netherlands, July 2000.

[21] T. Bailloeul, J. Duan, V. Prinet, and B. Serra, "Urban digital map updating from satellite high resolution images using GIS data as a priori knowledge," in Proceedings of the 2nd GRSS/ISPRS Joint Workshop on Remote Sensing and Data Fusion over Urban Areas, pp. 283-287, IEEE/ISPRS, Berlin, Germany, May 2003.

[22] M. Binard, Y. Cornet, and J. P. Donnay, "The usefulness of VHR images for public administrations in an urban hilly region," in Proceedings of the 25th Symposium of the EARSeL, Global Developments in Environmental Earth Observation from Space, A. Marçal, Ed., pp. 567-274, Millpress, Rotterdam, The Netherlands, June 2006.

[23] R. Lombardia and T. E. Urbanistica, "Specifiche tecniche per la realizzazione del database topografico alle scale 1:5000 e 1:10000, ver.01/01,” Italy.

[24] "Intesa Stato-Regioni-Enti Locali sui Sistemi Informativi Geografici Implementazione di un database geografico secondo le Specifiche di contenuto per la realizzazione dei Data Base Topografici di interesse generale - Versione Aerofotogrammetrica ed analisi delle problematiche legate alla convivenza nello stesso DataBase di dati acquisiti con precisioni diverse (DB multiscala)," 2004.

[25] A. Garzelli and F. Nencini, "PAN-sharpening of very high resolution multispectral images using genetic algorithms," International Journal of Remote Sensing, vol. 27, no. 15, pp. 32733292, 2006.

[26] C. A. Laben and B. V. Brower, "Process for enhancing the spatial resolution of multispectral imagery using pansharpening," US patent 6,011,875, 2000.

[27] Regione Lombardia, Specifiche tecniche db topografico scala 1:5000/10000, revision 2.0, november 2006, http://www
.regione.lombardia.it/servlet/BlobServer?blobcol=urlfilepath \&blobkey $=$ id\&blobtable $=$ Allegato \&blobwhere $=1048881686$ 142\&blobheadername2=Content-Disposition\&blobheadername $1=$ Content - Type $\&$ blobheadervalue $2=$ inline $\% 3 \mathrm{~B}+$ filename\%3Dspecifiche_tecniche_db_5000_10000.pdf\&blobheadervalue1=application/pdf, last accessed on 15 february 2007. 

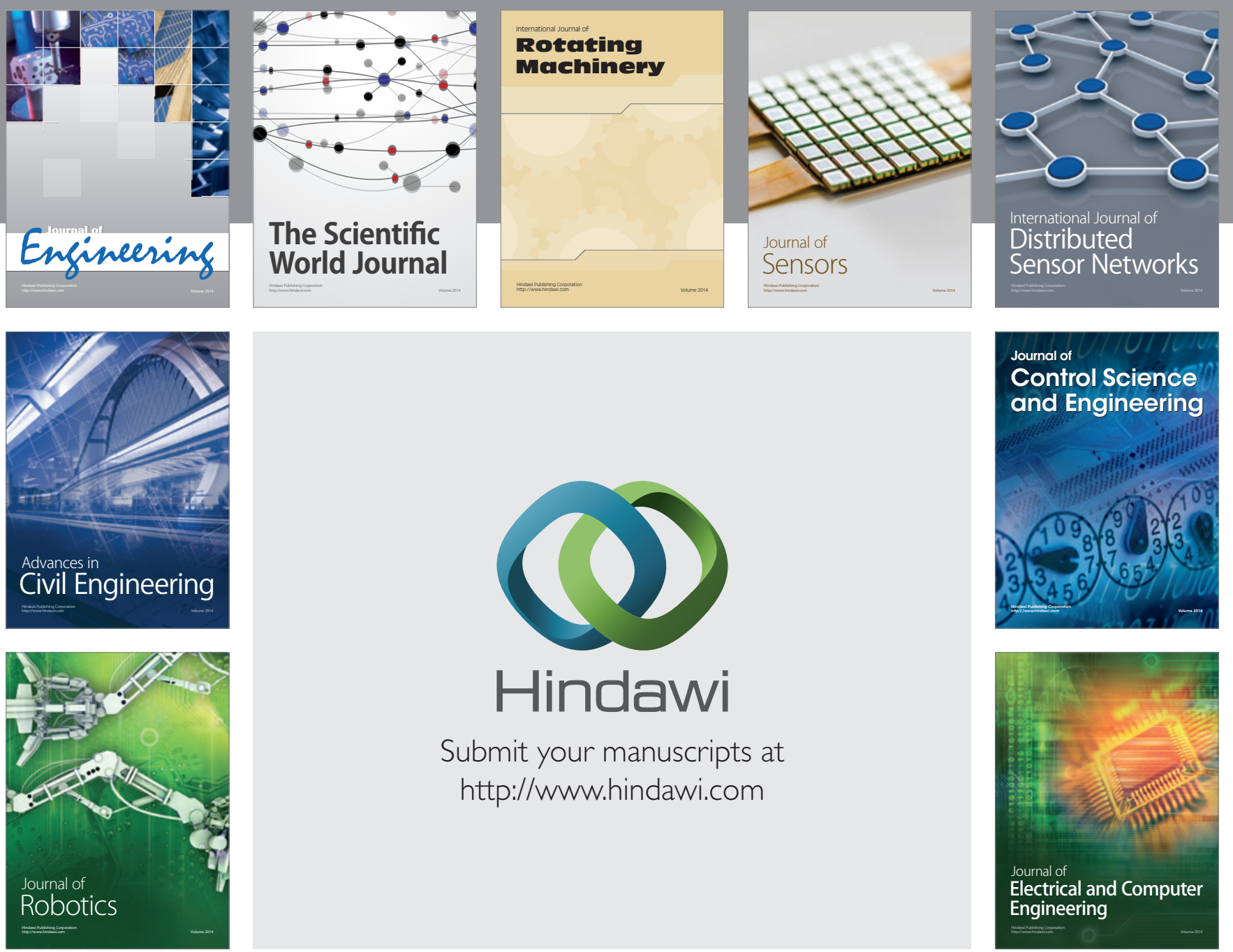

Submit your manuscripts at

http://www.hindawi.com
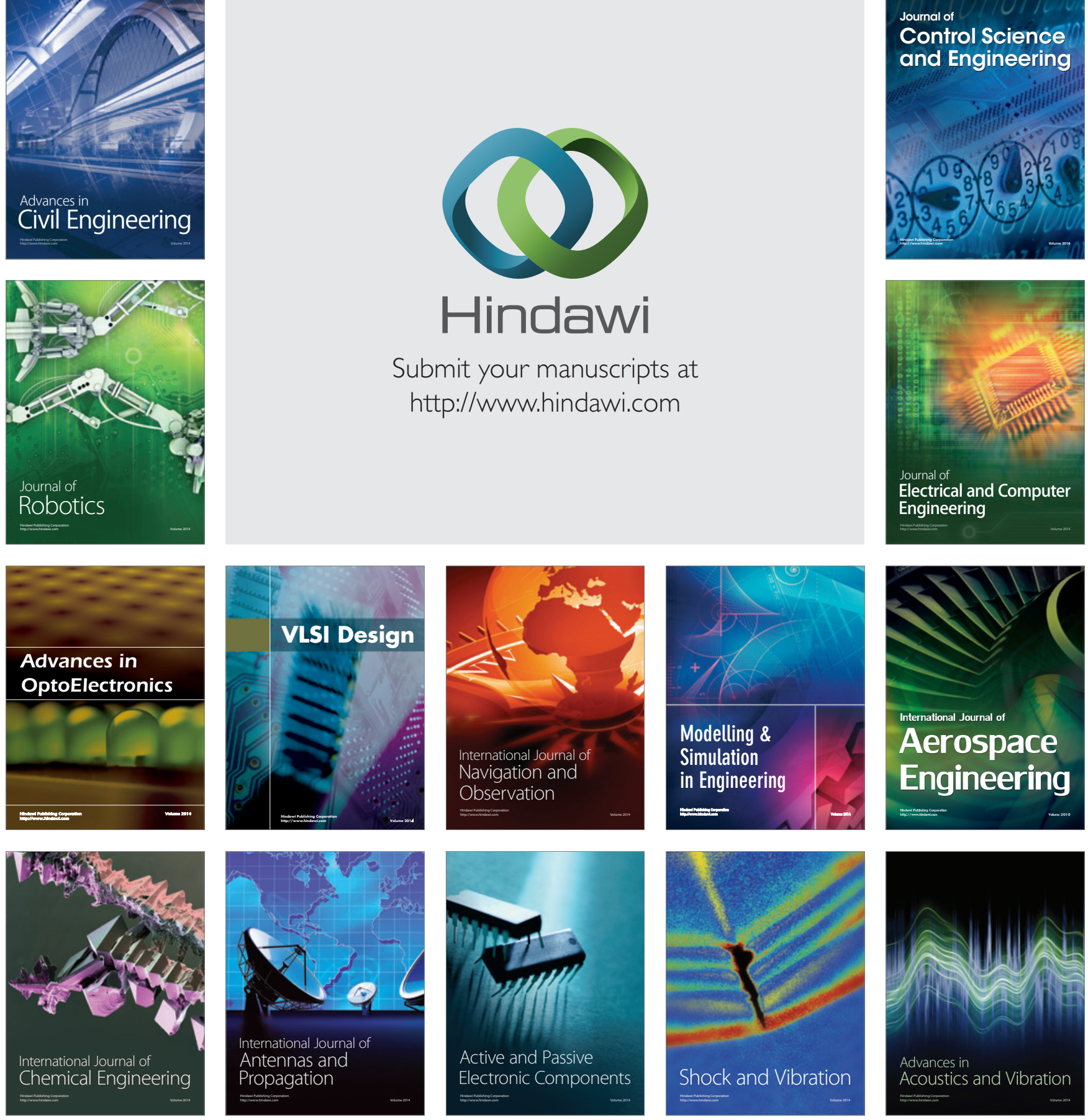